ORIGINAL ARTICLE

\title{
Prospective, randomised, double blind, controlled comparison of metoclopramide and pethidine in the emergency treatment of acute primary vascular and tension type headache episodes
}

\author{
M Cicek, O Karcioglu, İ Parlak, V Ozturk, O Duman, M Serinken, M Guryay
}

Emerg Med J 2004;21:323-326. doi: 10.1136/emj.2002.000356

\author{
See end of article for \\ authors' affiliations \\ Correspondence to: \\ Dr O Karcioglu, \\ Department of Emergency \\ Medicine, Dokuz Eylul \\ University, Medical \\ School, 35340, Inciraltı, \\ Izmir, Turkey; \\ ozgur.karcioglu@ \\ deu.edu.tr \\ Accepted for publication \\ 14 April 2003
}

\begin{abstract}
Study objective: To compare analgesic effects of metoclopramide (MTP), pethidine (PET), and combination of metoclopramide-pethidine (M-PET) in the treatment of adult patients with acute primary vascular and tension type headache admitted in the emergency department (ED).

Methods: All consecutive adult patients admitted into a university hospital ED in six months with acute vascular and tension type headache were recruited. The patients whose complaints had lasted no longer than seven days were randomised to four groups and thereby received $10 \mathrm{mg}$ MTP intravenously plus placebo intramuscularly (MTP), $10 \mathrm{mg}$ MTP intravenously plus $50 \mathrm{mg}$ PET intramuscularly (M-PET), $50 \mathrm{mg}$ PET intramuscularly plus placebo intravenously (PET); and intramuscular and intravenous placebo (PLC) in a blinded fashion. The patients were asked to report the degree of pain at $0,15,30$, and 45 minutes on visual analogue scale (VAS) and demographic data and any side effects encountered were recorded. Rescue medication was used if required by the patient because of poor pain relief.

Results: Data regarding 336 patients meeting inclusion criteria were analysed. Mean VAS values recorded at 45 minutes were significantly higher in PLC group than in others $(p=0.000)$. When the PLC group was excluded, VAS scores in MTP and M-PET groups were significantly lower than in PET group $(p=0.038)$. Though unimportant, the incidence of side effects recorded in PET group was found to be significantly higher than in the other groups $(p=0.003)$.

Conclusion: These data suggest that MTP produces more effective analgesia than PET in both vascular and tension type headache in patients with acute primary headache episodes.
\end{abstract}

$\mathrm{H}$ eadache is the chief complaint of $1.7 \%$ to $2.5 \%$ of the patients admitted to an emergency department (ED). ${ }^{1}$ Primary headache comprises $90 \%$ of the patients' underlying mechanisms. Migraine and tension type headache syndromes predominate a myriad of mechanisms of primary headache. ${ }^{2}$ Vascular score criteria established by Belgrade and Carleton have long been used to distinguish migraine headache and other types of vascular headache. ${ }^{3}$ These criteria are easy to use in emergency circumstances. On the other hand, The International Headache Society (IHS) criteria were developed to assess and diagnose tension headache. ${ }^{5}$

Even though most headache syndromes are benign, their treatment is sometimes challenging for the emergency physician. Metoclopramide (MTP) is used to relieve headache and is postulated to act via central antidopaminergic effects. ${ }^{6}$ The agent is a widely used antiemetic that is mainly free of serious side effects. Studies of intravenous MTP reported benefit over placebo and in one a success rate of $67 \% .{ }^{6}$ Some studies showed that MTP is effective in benign vascular type headache as a single agent. ${ }^{6-9}$ In contrast, two other studies argued that MTP failed to provide relief in migraine headache. $^{10}{ }^{11}$ One study showed that MTP is effective in organic headache. ${ }^{12}$ Our literature search did not reveal any study investigating results of MTP use in the treatment of tension type headache.

Though not specific for the disease, pethidine (PET) is also used in the treatment of vascular headache attacks. Some controlled studies comparing the effects of PET and placebo in the acute treatment of tension type headache found no statistically significant difference, although sample sizes were too small to draw conclusions. ${ }^{13} 14$ The main side effects of PET are nausea and vomiting, respiratory depression, smooth muscle spasm. ${ }^{15}$ Studies using PET in vascular headache produced clinical success rates of $22 \%$ to $50 \%{ }^{16}{ }^{17}$

The objective of this controlled study is to compare the effects of MTP, PET, and pethidine-metoclopramide (M-PET) combination in primary acute vascular and tension type headache attacks in the ED.

\section{METHODS}

This prospective, randomised, double blind, placebo controlled study was conducted in the six month study period between August 2000 and February 2001 after receiving approval from the institutional review board. All consecutive adult patients referred to the university ED with headache lasting shorter than seven days were asked to give informed consent for participation in the study. After excluding patients who refused to participate, all enrolled patients were randomised to one of four predetermined drug schemes.

Excluded from the study were the patients with secondary headache, altered mental status, abnormal vital signs, known to be pregnant, those with a history of epilepsy, Parkinson, or pheochromacytoma, or known allergy to the study drugs.

Diagnostic criteria for vascular headache included aura or anticipation of headache, nausea, vomiting, diarrhoea,

Abbreviations: ED, emergency department; MTP, metoclopramide; PET, pethidine; M-PET, metoclopramide-pethidine; VAS, visual analogue score 
anorexia; unilateral headache; photophobia or phonophobia; visual complaints; periodical headache; throbbing headache; childhood onset headache; history of motion sickness; family history of headache; headache triggered by certain foods; temporal asociation with menstruation. Emergency physicians responsible from the patients rated each criterion for all patients with headache. Patients with four or more positive items from this list were categorised as vascular headache, as recommended by vascular score criteria. $^{34}$ Diagnosis of tension headache was established using criteria derived from IHS. ${ }^{5}$ Forms containing the criteria were used to refer to for the assignment of the patients to the treatment arms.

Patients with vascular and tension headache were randomised to the same four drug regimens independently. Every patient received one intravenous (IV) and one intramuscular (IM) drug treatment. The table of random numbers was used to generate numbers placed on syringes containing study drugs. Nobody but one researcher who was not directly involved in drug administration and scoring of the patients was aware of the actual content of any given syringe. This procedure provided allocation concealment that blinded both the patients and caregivers.

The four drug regimens were formed as follows: $10 \mathrm{mg}$ IV metoclopramide plus IM placebo (MTP), $10 \mathrm{mg}$ IV metoclopramide plus $50 \mathrm{mg}$ IM pethidine (M-PET), IV placebo plus $50 \mathrm{mg}$ IM pethidine (PET), and IV placebo plus IM placebo (PLC).

Intravenous normal saline infusion was administered for all patients via peripheral veins. Infusion rate ranged from "to keep open" to $100 \mathrm{ml}$ per hour. Data regarding vital signs, demographic variables, associated illnesses including migraine, medications used within the past 24 hours, side effects and complications encountered were recorded in the data forms. Vital signs were recorded every 15 minutes after the administration of study drugs.

The patients were asked to report pain intensity at the time of drug administration (time zero) as well as at 15, 30, and 45 minutes on a $100 \mathrm{~mm}$ visual analogue scale (VAS) as well as demographic data and any side effects encountered. Rescue medication was used if required by the patient because of poor pain relief. The drug choice was at the physicians' discretion and included MTP, non-steroidal antiinflammatory drugs, and opioids. Rescue drugs could only be administered after 60 minute of the study treatment. Side effects were monitored for all patients for four hours after the treatment, regardless of administration of rescue medication. The measurements and recordings of vital signs and pain intensities were undertaken by interns and junior residents unaware of the study drugs and allocation of the patients.

Percentage of the cases requiring rescue medication in each group was compared using logistic regression analysis. Comparisons of binary data derived from the same patient (for example, total volume infused and need for rescue drug) were undertaken with a paired $t$ test. The experimental two tailed $\alpha$ error was set at 0.05 . With sample size calculations based on unmatched comparisons of proportions, enrollment of 35 patients in a group offered a minimum pretrial power of 0.8 to detect a difference in frequency of clinical improvement of $30 \%$ or greater between the treatments.

\section{RESULTS}

Four hundred and twenty five adult patients visited our ED during the six month study period because of headache and data forms were filled. Among those, 89 (20.9\%) were excluded from analysis: 51 (57\%) were found to have secondary causes of headache, 27 (30\%) refused treatment, six $(6.7 \%)$ complained of headache lasting for longer than seven days, three $(3.3 \%)$ were being treated for epilepsy, and two $(2.2 \%)$ were pregnant. Secondary causes of headache $(\mathrm{n}=5 \mathrm{l})$ included infection and/or fever outside central nervous system $(n=31,60 \%)$, head injury $(n=4,7.8 \%)$, intracranial haemorrhage $(n=4,7.8 \%)$, hypertension $(n=3$, $5.8 \%)$, brain tumour $(\mathrm{n}=3,5.8 \%)$, transient ischaemic attack $(\mathrm{n}=2,3.9 \%)$, glaucoma $(\mathrm{n}=1,1.9 \%)$, trigeminal neuralgia $(\mathrm{n}=1,1.9 \%)$, alcohol withdrawal $(\mathrm{n}=1,1.9 \%)$, and carbon monoxide intoxication $(\mathrm{n}=1,1.9 \%)$.

Thus 336 cases $(79.1 \%)$ were enrolled into the study and were assigned to either acute benign vascular or tension type headache groups. There were not any patients who met the criteria for inclusion in both groups or neither of the groups. Vascular headache group comprised 196 cases (MTP group 50, M-PET 49, PET 49, and PLC 48 patients) while tension headache group consisted 140 patients evenly randomised to four drug regimens $(n=35$ each). Female to male ratio was 4.25, (7.1 in vascular headache group and 2.5 in tension headache group). Mean (SD) age of patients with vascular headache was 38.8 (11.1); while the corresponding figure in the tension headache group was 42.1 (13.8)).

Mean (SD) weight of the subjects was 68.4 (12.7) kg and mean age was 40.2 (12.4). Total volumes of normal saline infused to the patients during the four hour study period varied from 100 to $400 \mathrm{ml}$.

\section{Need for rescue drug}

Tension type headache group

The number of patients who required rescue drugs was 58 $(41.4 \%)$. The percentages of patients who needed rescue drugs in the tension headache group were $14.2 \%$ for MTP; $37.1 \%$ for M-PET; $42.8 \%$ for PET, and $71.4 \%$ for placebo (table 1). In patients with tension type headache, allocation to drug regimens had a significant impact on the rates of rescue drug use $\left(\chi^{2}=23.902, p=0.000\right)$. On the other hand, need for rescue drug did not change with the weight, age, sex, use of analgesic medications in history, and total volume infused within the study period $(p=0.902, p=0.892$, $\mathrm{p}=0.809, \mathrm{p}=0.573, \mathrm{p}=0.226$, respectively).

The relation between time zero VAS values and need for rescue medication was found to be significant. Patients with higher VAS values needed rescue drugs more frequently $(\mathrm{p}=0.002)$.

\section{Vascular headache group}

Sixty four patients in the vascular headache group $(32.6 \%)$ needed rescue drugs. The percentages of patients who needed rescue drugs in the vascular headache group were $14 \%$ for MTP, $20.4 \%$ for M-PET, 40.8 for PET, and $56.6 \%$ for placebo (table 1). The rates of rescue drug use were affected by allocation to drug regimens $\left(\chi^{2}=24.890, p=0.000\right)$. Patients with low vascular scores had a higher rate of need for rescue drugs $(\mathrm{p}=0.042)$.

In the vascular headache group, there was no significant difference between MTP and M-PET groups regarding need for rescue medication $(p=0.426)$ while MTP group was significantly different from PET and PLC groups in which the

\begin{tabular}{llll}
$\begin{array}{l}\text { Table } 1 \\
\text { each headache group }\end{array}$ & $\begin{array}{l}\text { Ratios of patients who requested rescue drugs in } \\
\text { Vascular type } \\
\text { Number (\%) }\end{array}$ & $\begin{array}{c}\text { Tension type } \\
\text { Number (\%) }\end{array}$ & $\begin{array}{l}\text { Whole group } \\
\text { Number (\%) }\end{array}$ \\
\hline MTP & $7(14)$ & $5(14.2)$ & $12(14.1)$ \\
M-PET & $10(20.4)$ & $13(37.1)$ & $23(27.3)$ \\
PET & $20(40.8)$ & $15(42.8)$ & $35(41.6)$ \\
Placebo & $27(56.2)$ & $25(71.4)$ & $52(62.6)$ \\
Total & $64(32.6)$ & $58(41.4)$ & $122(36.3)$ \\
\hline
\end{tabular}




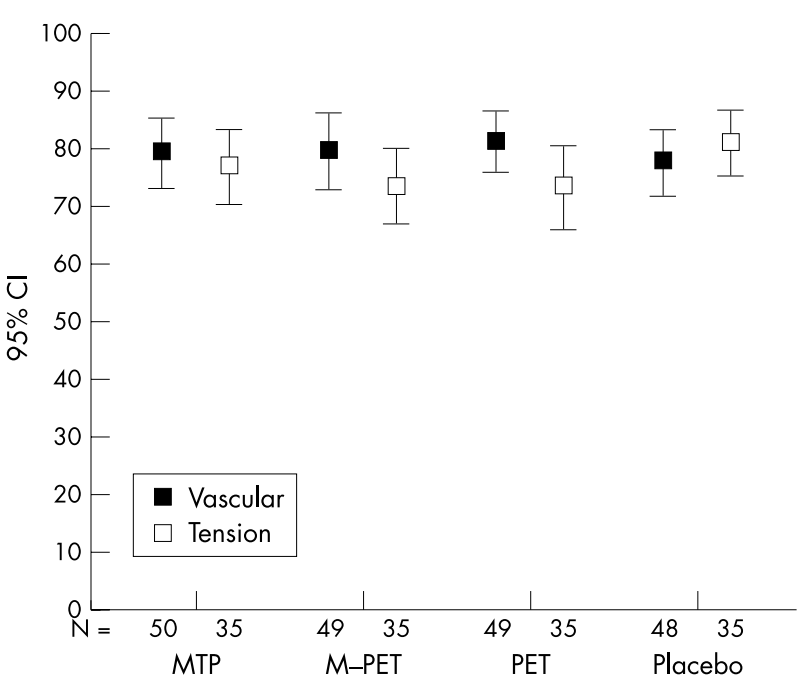

Type of drug

Figure 1 Mean VAS scores in vascular and tension type headache groups recorded just before the treatment (time zero).

largest number of patients who requested rescue drugs were recorded $(\mathrm{p}=0.000, \mathrm{p}=0.007$, respectively).

\section{VAS scores}

Figures 1 and 2 depict mean VAS scores in vascular and tension type headache groups recorded before the treatment and 45 minutes later, respectively.

Mean VAS score of PLC group was significantly higher than the others $(p=0.000)$. When we excluded PLC group, mean VAS score of PET group was significantly higher than the others $(p=0.038)$. Mean VAS score of MTP group was equal to those of M-PET group $(p=1.000)$. Mean VAS score of PET group was significantly higher than MTP group $(p=0.040)$. Mean VAS scores were not significantly related to the total volume infused (paired $t$ test, $\mathrm{p}=0.473$ ).

\section{Comparison of side effects}

Table 2 indicates distribution of side effects among the four drug groups.

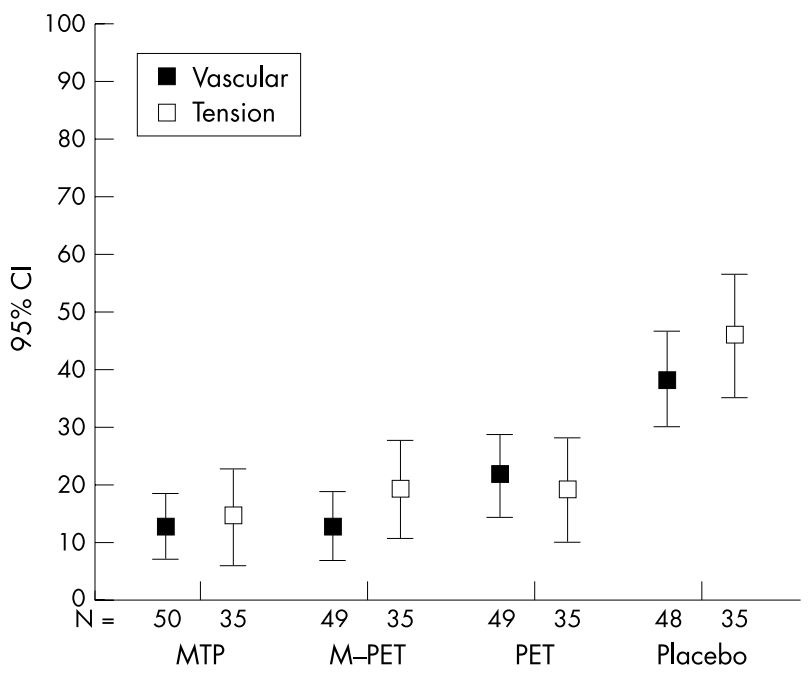

Type of drug

Figure 2 Mean VAS scores in vascular and tension type headache groups recorded at 45 minutes after the beginning of the drug treatment.
Tension type headache group

The frequencies of side effects in tension type headache groups were $22.9 \%$ for MTP; $45.7 \%$ for M-PET; $54.3 \%$ for PET, and $14.3 \%$ for PLC $\left(\chi^{2}=16.486, p=0.001\right)$.

\section{Vascular headache group}

The corresponding rates in the vascular group were $38 \%$ for MTP; $52.1 \%$ for M-PET; $57.1 \%$ for PET, and $12.5 \%$ for PLC $\left(\chi^{2}=24.128, \mathrm{p}=0.000\right)$.

PLC group had the least frequency of side effects when compared with MTP group, M-PET group, and PET group in increasing order $(\mathrm{p}=0.001, \mathrm{p}=0.000, \mathrm{p}=0.000$ respectively). The observed frequency of side effects was not found significantly related to sex, age, and weight of the patients and the total volume infused $(p=0.376, p=0.055, p=0.054$, $p=0.197$ respectively). The incidence of side effects observed in the study period was not significantly related to the administration of rescue medication $(\mathrm{p}=0.164)$.

\section{DISCUSSION}

Most patients visiting EDs because of headache are diagnosed to have acute primary headache. Many trials have been conducted on the treatment of the entity. These included investigations on the effect of MTP on migraine episodes. ${ }^{3-11}$ 18-22 In contrast, a literature search did not reveal any studies on the effect of MTP on tension type headache. Only one study used MTP in the treatment of organic headache. ${ }^{12}$ PET was subject to research in the treatment of acute primary headache with its well known analgesic properties. ${ }^{3}{ }^{13} 14^{16} 6^{23-25}$ This study is unique in comparing MTP and PET in the treatment of acute vascular and tension type headache in the emergency setting.

\section{Efficacy in tension type headache}

The lowest percentages of patients who requested rescue drugs were those treated with MTP. Percentage of patients requiring rescue drugs was $14.2 \%$ for MTP and $42.8 \%$ for PET. Ellis et al reported the corresponding ratio for MTP as $20 \%$ in a study with a small sample size. ${ }^{7}$

MTP was the most effective analgesic agent administered in this study. PET $(50 \mathrm{mg})$ was found more effective in treating acute attacks of tension type headache than PLC. This result is different from the findings of Harden et al in which PET in the same dose was only as effective as PLC. ${ }^{14}$ Broader and well designed studies are required to investigate the exact causes of the difference. Harden et al compared effects of ketorolac and pethidine in patients with tension type headache in another study ${ }^{13}$ and found that two hour efficacy of $60 \mathrm{mg}$ ketorolac was more favourable than $50 \mathrm{mg}$ pethidine.

\section{Efficacy in vascular headache}

Again, the most successful drug regimen in the vascular headache group was MTP in the given dose. Success rate of MTP in treating vascular headache in our study was $86 \%$ compared with $43 \%$ of PLC. This rate is much higher than those of Coppola et al (46\% and $29 \%$, respectively) who compared MTP with prochlorperazine and PLC in a double blind randomised study. ${ }^{10}$ They did not find any statistically significant difference between scores of MTP and PLC groups.

In a study comparing MTP and prochlorperazine in migraine headache, Jones et $a l^{11}$ reported that rescue drug was needed for $79 \%$ and $57 \%$ of patients, respectively, much more frequent than the figures in this study (14\%). The difference could result from varying baseline severity of headache or from cultural differences leading to patients' bias of reporting pain intensity.

In terms of analgesic efficacy (decrease in pain intensity), patients receiving MTP relieved significantly better than 
Table 2 Distribution of side effects among drug groups

\begin{tabular}{llllll}
\hline & $\begin{array}{l}\text { MTP } \\
(\mathbf{n = 8 5 )}\end{array}$ & $\begin{array}{l}\text { M-PET } \\
(\mathbf{n = 8 4 )}\end{array}$ & $\begin{array}{l}\text { PET } \\
(\mathbf{n = 8 4 )}\end{array}$ & $\begin{array}{l}\text { Placebo } \\
(\mathbf{n}=83)\end{array}$ & Total=336 \\
\hline Drowsiness/light & $\mathbf{n}(\%)$ & $\mathbf{n}(\%)$ & $\mathbf{n}(\%)$ & $\mathbf{n}(\%)$ & $\mathbf{n}(\%)$ \\
sedation & $17(20)$ & $27(32)$ & $22(26.2)$ & $4(4.8)$ & $70(20.8)$ \\
Dizziness & $3(3.5)$ & $17(20)$ & $24(28.5)$ & $1(1.2)$ & $45(13.3)$ \\
Nausea & $6(7)$ & $11(13)$ & $19(22.6)$ & $5(6)$ & $41(12.2)$ \\
Dysphoria & $4(4.7)$ & $1(1.1)$ & $2(2.3)$ & 0 & $7(2)$ \\
Restlessness & $3(3.5)$ & 0 & 0 & 0 & $3(0.8)$ \\
Flushing & 0 & $2(2.3)$ & $3(3.5)$ & 0 & $5(1.4)$ \\
Others & 0 & $3(3.5)$ & $2(2.3)$ & $1(1.2)$ & $6(1.7)$ \\
Total & $33(38.8)$ & $61(72.6)$ & $72(85.7)$ & $11(13)$ & $177(52.6)$ \\
\hline & & & & & \\
\hline
\end{tabular}

patients treated with other agents (PET and PLC); this result is similar with the comparison study of (MTP and ibuprofen in migraine) by Ellis et al. ${ }^{7}$ In contrast, results by Jones et a ${ }^{11}$ show that the decrease in pain intensity after MTP administration was as high as $83 \%$, which is greater than in this study.

Decreases in VAS scores elicited from patients with acute migraine episodes in this study were found significant after MTP use. For example, mean decrease at 45 minutes was $6.5 \mathrm{~cm}$, which is greater than $4.3 \mathrm{~cm}$ found in the study by Cameron et al. ${ }^{8}$ Mean VAS decrease in MTP and PLC (6.6 and 3.9, respectively) was higher than the results of Tek et al (2.46 and 1.69, respectively). ${ }^{6}$ Mean VAS in PET group after drug administration was higher than MTP and M-PET groups.

Side effects were seen in 126 patients $(37.8 \%)$. The most common side effect was drowsiness or light sedation, which was noted in 70 cases $(20.8 \%)$. Although the figure seems to be somewhat high, side effects with serious outcomes were not encountered in any patient in this trial. The incidence of side effects was also unrelated to the actual quantity of the volume infused in the patient.

One drawback of the study could be the short follow up period of the patients as to the duration and course of side effects. Similarly, the variation of total volume of normal saline infused could be questioned to represent a confounding factor for analgesic efficacy. None the less, neither the need for rescue drug nor the mean VAS scores were found related to the infused volume.

In conclusion, these data suggest that MTP produces more effective analgesia than PET in both vascular and tension type headache in adult patients with acute primary headache episodes.

\section{Authors' affiliations \\ M Cicek, O Karcioglu, I Parlak, O Duman, M Serinken, M Guryay,}

Department of Emergency Medicine, Dokuz Eylul University Medical School, Izmir, Turkey

V Ozturk, Department of Neurology, Dokuz Eylul University Medical School

Funding: none.

Conflicts of interest: none declared.

\section{REFERENCES}

1 Spence J. Migraine and other causes of headache. Ann Emerg Med 1996;27:448-50.

2 Sztajnkrycer M, Jauch EC. Unusual headache. Emerg Med Clin North Am 1998;16:741-60.

3 Belgrade $M J$, Ling $\amalg$, Schleevogt $M B$, et al. Comparison of single-dose meperidine, butorphanol, and dihydroergotamine in the treatment of vascular headache. Neurology 1989;39:590-2.
4 Carleton SC, Shesser RF, Pietrezak MP, et al. Double-blind, multicenter trial to compare the efficacy of intramuscular dihydroergotamine plus hydroxyzine versus intramuscular meperidine plus hydroxyzine for the emergency department treatment of acute migraine headache. Ann Emerg Med 1998;32:129-38.

5 Headache Classification Committee of the International Headache Society. Classification and diagnostic criteria for headache disorders, cranial neuralgias and facial pain. Cephalgia 1988;8(suppl 7):1-96.

6 Tek DS, McClellan, Olshaker JS, et al. A prospective, double-blind study of metoclopramide hydrocloride for the control of migraine in the emergency department. Ann Emerg Med 1990;19:1083-7.

7 Ellis GL, Delaney J, DeHart DA, et al. The efficacy of metoclopramide in the treatment of migraine headache. Ann Emerg Med 1993;22:191-5.

8 Cameron JD, Lane PL, Speechley M. Intravenous chlorpromazine vs intravenous metoclopramide in acute migraine headache. Acad Emerg Med 1995:2:597-602.

9 MacCumber MW, Jaffe GJ, McCuen BW. Treatment of migraine headache after ocular surgery with intravenous metoclopramide hydrochloride. Am J Ophthalmol 1996;121:96-7.

10 Coppola M, Yealy DM, Leibold RA. Randomized, placebo-controlled evaluation of prochlorperozine versus metoclopramide for emergency department treatment of migraine headache. Ann Emerg Med 1995;26:541-6.

11 Jones J, Pack S, Chun E. Intramuscular prochlorperazine versus metoclopramide as single-agent therapy for the treatment of acute migraine headache. Am J Emerg Med 1996;14:262-4.

12 Gross DW, Donat JR, Boyle CA. Dihydroergotamine and metoclopramide in the treatment of organic headache. Headache 1995;35:637-8.

13 Harden RN, Rogers D, Fink K, et al. Controlled trial of ketorolac in tensiontype headache. Neurology 1998;50:507-9.

14 Harden RN, Gracely RH, Carter T, et al. The placebo effect in acute headache management: ketorolac, meperidine, and saline in the emergency department. Headache 1996;36:352-6.

15 Gilman AG, Rall TW, Nies AS, et al. The pharmacological basis of therapeutics. 8th edn. New York: McGraw-Hill, 1991.

16 Lane PL, McLellan BA, Baggoley CJ. Comparative efficacy of chlorpromazine and meperidine with dimenhydrinate in migraine headache. Ann Emerg Med 1989;18:360-5.

17 Klappen JA, Stanson J. Current emergency treatment of severe migraine headaches. Headache 1993:33:560-2

18 Hugues FC, Lacoste JP, Danchot J, et al. Repeated doses of combined oral lysine acetylsalicylate and metoclopramide in the acute treatment of migraine. Headache 1997;37:452-4.

19 Chabriat H, Joire JE, Danchot J, et al. Combined oral lysine acetylsalicylate and metoclopramide compared in the acute treatment of migraine: a multicentre double-blind placebo-controlled study. Cephalgia 1994; 14:297-300.

20 Pradalier A, Guerard des Lauriers A, Scheck F, et al. Calcium carbasalatemetoclopramide combination versus dihydroergotamine in the treatment of migraine attacks. Pathol Biol 1995;43:806-13.

21 Henry P, Hiesse-Provost O, Dillenschneider A, et al. Efficacy and tolerance of an effervescent aspirin-metoclopramide combination in the treatment of migraine attack. Randomized double-blind study using a placebo. Presse Med 1995:24:254-8.

22 Scherl ER, Wilson JF. Comparison of dihydroergotamine with metoclopramide versus meperidine with promethazine in the treatment of migraine. Headache 1995; 35:256-9.

23 Davis CP, Torre Pr, Williams C, et al. Ketorolac versus meperidine-pluspromethazine treatment of migraine headache: evaluations by patients. Am J Emerg Med 1995;13:146-50.

24 Larkin GL, Prescott JE. A randomized, double-blind, comparative study of the efficacy of ketorolac tromethamine versus meperidine in the treatment of severe migraine. Ann Emerg Med 1992;21:985-6.

25 Stiell IG, Dufour DG, Moher D, et al. Methotrimeprazine versus meperidine and dimenhydrinate in the treatment of severe migraine: a randomized, controlled trial. Ann Emerg Med 1991;20:1201-5. 